\title{
ELICITATION AND TREATMENT WITH PRECURSORS OF PHENOLICS SYNTHESIS IMPROVE LOW-MOLECULAR ANTIOXIDANTS AND ANTIOXIDANT CAPACITY OF BUCKWHEAT SPROUTS
}

\author{
Michat Świeca ${ }^{\bowtie}$ \\ Department of Biochemistry and Food Chemistry, University of Life Sciences in Lublin \\ Skromna 8, 20-704 Lublin, Poland
}

\begin{abstract}
Background. Recently, an increase of interest in the modification of food products on each step of production (breeding, production technology, storage condition) is observed. Nutritional properties as well as level and activity of bioactive compounds in plant-origin food may be modified using a range of technological and biotechnological practices and elicitation should be mentioned between them.

Material and methods. Elicitation with willow bark infusion supported by feeding with the phenylpropanoid pathway precursors were used for improving the quality of buckwheat sprouts. Special emphasis has been placed on the metabolomic and biochemical changes and the mechanism of overproduction of low-molecular antioxidants.

Results. The accumulation of phenolics is caused by stimulation of two main enzymes the phenylpropanoid pathway (tyrosine ammonia-lyase and phenylalanine ammonia-lyase). Tyrosine ammonia-lyase activities were effectively induced by feeding with tyrosine (about four times that of the control), whereas phenylalanine ammonia-lyase activity was the highest in the elicited control sprouts and those fed with shikimic acid (an increase by $60 \%$ compared to the control). Shikimic acid feeding (both elicited and non-elicited sprouts) effectively improved the total phenolics (by about $10 \%$ and $20 \%$, respectively), condensed tannins (by about $30 \%$ and $28 \%$, respectively), and flavonoids (by about $46 \%$ and $70 \%$, respectively). Significant increase of vitexin, rutin, chlorogenic acid and isoorientin contents was also observed. The treatments increased the ascorbic acid content, too. Total antioxidant capacity of sprouts was most effectively increased by feeding with shikimic acid and further elicitation.

Conclusion. The studies transfer biotechnology commonly used for the induction of overproduction of secondary metabolites in plant cell line systems to low-processed food production. The obtained results could be used for better understanding of the effect of elicitation and precursor feeding on antioxidants production and contribute to improving the buckwheat sprouts quality.
\end{abstract}

Key words: antioxidant activity, buckwheat sprouts, elicitation, low-molecular weight antioxidants, phenylpropanoid pathway, precursor feeding

\section{INTRODUCTION}

An increased interest has been noticed in the modification of food along each step of its production (breeding, production technology, storage condition). Briefly speaking nutritional properties as well as the level and activity of bioactive compounds present in plant-origin food may be modified using a range of technological 
and biotechnological practices. There are two main ways of improving the antioxidant content in sprouts. The first one comprises genetic manipulation and is based on metabolic engineering (Liu et al., 2007). The second involves modification of the sprouting process, including elicitation and supported elicitation (Baenas, et al., 2014).

Elicitors are chemicals or biofactors from various sources, which can induce physiological changes in the target living organism. It may include abiotic elicitors such as metal ions, inorganic compounds, chilling etc., and biotic elicitors from fungi, bacteria, viruses, plant cell wall components, as well as chemicals that are released at the attack site by plants under a pathogen or herbivore attack (e.g., signaling compounds such as salicylic acid, jasmonic acid) (Baenas et al., 2014; Matkowski, 2008). Willow bark is an excellent source of salicylic acid and its derivatives (Durak and Gawlik-Dziki, 2014) and its infusion have already been used for induction of plants metabolism (Gawlik-Dziki et al. 2013; Świeca and Dziki, 2015). Salicylic acid (SA) is a well-known inducer of plant systematic acquired resistance (SAR) in plant-pathogen interaction. SA quickly accumulates at the site of infection during a pathogen attack, as well as during a hypersensitive reaction, and it spreads to other parts of the plant to induce a wide range of defense responses (Yuan and Lin, 2008).

The pro-health quality of low-processed food, e.g., sprouts, is strongly determined by its chemical composition (Pérez-Balibrea, et al., 2011; Świeca and Baraniak, 2014a; 2014b; 2014c). Phenolics and ascorbic acid - compounds with well-documented biological activity (Fang et al., 2002; Gawlik-Dziki et al., 2012) - play a very important role in the creation of food bioactivity. The effectiveness of antioxidants results from various mechanisms of activity: antioxidants could inhibit free-radical reaction by inhibiting lipid radical formation, disrupting propagation of chain autooxidation reactions, suppressing singlet oxygen, they could act as factors that aid in reducing hydrogen peroxides to stable compounds, as compounds chelating transition metal ions and as inhibitors of pro-oxidative enzymes (Carocho and Ferreira, 2013). Thus, antioxidant activity, as the fundamental property of food, is important for its health protecting ability, including its antimutagenic, anticarcinogenic, antiobesity and antiaging effects.

So far, studies aimed to improve the antioxidant composition of sprouts have involved optimizing biosynthesis through the modifications of culture conditions (Khattak et al., 2007; Shett and McCue, 2003; Świeca et al., 2012), precursor feeding and biotransformation (Pérez-Balibrea et al., 2011; Świeca et al., $2014 \mathrm{c}$ ), as well as elicitation and stress induced production (Gawlik-Dziki et al., 2013; Kim et al., 2011; Tsurunaga et al., 2013; Świeca, 2015). Elicitors increase the activity of key enzymes involved in the synthesis of low-molecular antioxidant e.g. activities of tyrosine/phenylalanine ammonia-lyase, chalcon synthase in the phenylpropanoid pathways (phenolics synthesis). Additionally the effectiveness of synthesis may be enhanced by enrichment of culture with precursors e.g. shikimic acid, phenylalanine and tyrosine (phenolics synthesis) (Baenas et al., 2014; Świeca et al., 2014c) or galactose, mannose (ascorbic acid synthesis) (Gallie, 2013). Most importantly, there are only a few studies concerning the mechanisms of obtaining the desirable features.

Therefore, in this study, a metabolomic and biochemical analysis (including an analysis of low-molecular antioxidants contents and activities involved in phenolic synthesis and metabolism) was performed on buckwheat sprouts. The effects of elicitation with Salix bark infusion and the phenylpropanoid pathway precursors feeding on the the changes in antioxidant capacity were also determined. The study aimed to widen the knowledge about the mechanisms of elicitation, as a result of which the health promoting properties of plant-food products could be strengthened.

\section{MATERIAL AND METHODS}

\section{Chemicals}

Ferrozine (3-(2-pyridyl)-5,6-bis-(4-phenyl-sulphonic acid)-1,2,4-triazine), ABTS (2,2'-azino-bis(3-ethylbenzothiazoline-6-sulphonic acid), linoleic acid, ammonium thiocyanate, polyvinylpyrrolidone and haemoglobin were purchased from Sigma-Aldrich company (Poznań, Poland). All other chemicals were of analytical grade. 


\section{Materials}

Buckwheat (Fagopyrum esculentum Moench) seeds were purchased from PNOS S.A. in Ożarów Mazowiecki, Poland. Seeds were sterilized in $1 \%(\mathrm{v} / \mathrm{v})$ sodium hypochloride for $10 \mathrm{~min}$, then drained and washed with distilled water until they reached neutral $\mathrm{pH}$. After that seeds were placed in distilled water $(\mathrm{C}$, control and $\mathrm{E}$, elicitor treatment) or phenolic precursor solution $(0.1 \mathrm{mM}$ shikimic acid $-\mathrm{Sh}$ and $\mathrm{Sh}+\mathrm{E} 0.1 \mathrm{mM}$ L-phenylalanine - Phe and Phe+E; 0.1 mM L-tyrosine - Tyr and Tyr+E) and soaked for $4 \mathrm{~h}$ at $25^{\circ} \mathrm{C}$. Seeds were dark germinated for 3 days in a growth chamber on Petri dishes ( $\phi 125 \mathrm{~mm}$ ) lined with absorbent paper (approximately 400 seeds per dish). Seedlings were watered daily with $5 \mathrm{~mL}$ of Milli-Q water. For elicitor treatment $(\mathrm{E}, \mathrm{Sh}+\mathrm{E}, \mathrm{Phe}+\mathrm{E}$ and $\mathrm{Tyr}+\mathrm{E}), 1$-day-old sprouts were watered with $5 \mathrm{ml}$ of $0.01 \%$ infusion of Salix myrsinifolia bark. The plates were then covered and sprouts were germinated under control conditions. Bark of willow (Salix daphnoides), obtained from an ecological farm in Poland, was dried and pulverized in a laboratory mill. Elicitor solution was prepared by brewing $1 \mathrm{~g}$ of the material with $100 \mathrm{~mL}$ of boiling water for $15 \mathrm{~min}$.

\section{Analysis of low-molecular weight antioxidants - PHENOLICS}

Extraction procedure. Flours (0.25 g in triplicate) were extracted three times with $4 \mathrm{ml}$ of ethanol: water $(80: 20, \mathrm{v} / \mathrm{v})$. After centrifugation $(10 \mathrm{~min}, 6800 \times \mathrm{g})$ fractions were collected, combined and used for further analysis of phenolics and antioxidant capacity.

Total phenolics. The amount of total phenolics was determined using Folin-Ciocalteau reagent (Singleton et al., 1974). The amount of total phenolics was calculated as a gallic acid equivalent (GAE) in $\mathrm{mg}$ per $\mathrm{g}$ of dry mass (d.m.).

Total flavonoids content was determined according to the method described by Lamaison and Carnat (1990). Total flavonoids content was calculated as a quercetin equivalent $(\mathrm{QE})$ in $\mathrm{mg}$ per $\mathrm{g}$ of dry mass (d.m.).

Condensed tannin content was determined according to the method described by Sun et al. (1998). Condensed tannin content was calculated as a $(+)$-catechin equivalent (CE) in mg per $g$ of dry mass (d.m.).
Quantitative - qualitative analysis of phenolic. Samples were analysed with a Varian ProStar high-performance liquid chromatography (HPLC) system separation module (Varian, Palo Alto, CA, USA) equipped with Varian ChromSpher C18 reverse phase column $(250 \mathrm{~mm} \times 4.6 \mathrm{~mm})$ and ProStar DAD detector (Świeca and Baraniak, 2014b). Quantitative determinations were carried out with the external standard calculation, using calibration curves of the standards. Phenolics were expressed in $\mu \mathrm{g}$ per gram of dry mass (d.m.).

\section{- EXTRACTION AND DETERMINATION OF VITAMIN C CONTENT}

Total ascorbic acid content was determined as a sum of ascorbic and dehydroascorbic acid, according to modified versions of the methods described earlier by Campos et al. (2009). Briefly, $500 \mathrm{mg}$ of fresh sprouts was extracted two times with $2 \mathrm{~mL}$ of $50 \%(\mathrm{w} / \mathrm{v}) \mathrm{m}$ -phosphoric acid (MPA). The mixture was centrifuged at $16,000 \mathrm{~g}$, and extracts were combined and used for further determination. $500 \mu \mathrm{l}$ of extract was mixed with $500 \mu \mathrm{l}$ ditiotreitol $30 \mathrm{mM}$ in $0.5 \mathrm{M}$ Trizma buffer for $5 \mathrm{~min}$. Then, $650 \mu \mathrm{l}$ of $5 \%$ (w/v) MPA was added. Samples were filtered using a $0.45 \mu \mathrm{m}$ Millipore and analysed with a Varian ProStar HPLC System separation module (Varian, Palo Alto, CA) equipped with a Varian ChromSpher C18 reverse phase column (250 $\times 4.6 \mathrm{~mm}$ ) column and a ProStar $325 \mathrm{UV}$-Vis detector. The column thermostat was set at $25^{\circ} \mathrm{C}$. The separation was performed under isocratic elution conditions using a mobile phase consisting of $30 \mathrm{mM} \mathrm{KH_{2 }} \mathrm{PO}_{4}$ adjusted with $5 \mathrm{M} \mathrm{HCl}$ to $\mathrm{pH} 3$, at a flow-rate of 0.8 $\mathrm{mL} \cdot \mathrm{min}^{-1}$ and detection at $245 \mathrm{~nm}$. Quantitative determination was conducted with an external standard calculation, using calibration curves of the standard. Ascorbic acid content was expressed in $\mu \mathrm{g}$ per $1 \mathrm{~g}$ of fresh mass (FM).

\section{- EXTRACTION AND DETERMINATION OF CHLOROPHYLLS AND CAROTENOIDS}

Chlorophylls and carotenoids were analyzed according to the method described by Lin et al. (2013). Chlorophylls and carotenoids were eluted overnight from the freeze-dried leaves samples $(0.05 \mathrm{~g})$ with $2 \mathrm{~mL}$ $80 \%(\mathrm{v} / \mathrm{v})$ acetone at $4^{\circ} \mathrm{C}$. The sample was then centrifuged at $13,000 \mathrm{~g}$ for $5 \mathrm{~min}$. The supernatant was applied to determine the absorbance of chlorophyll a, 
chlorophyll $\mathrm{b}$ and carotenoids in acetone, as measured with a spectrophotometer, at the respective wavelengths of 663,645 and $470 \mathrm{~nm}$. Concentrations of chlorophyll a, chlorophyll $\mathrm{b}$ and carotenoids were determined from the following equations:

$$
\text { Chlorophyll a }=12.72 \text { A663 }-2.59 \times \text { A } 645
$$

Chlorophyll b $=22.88 \times \mathrm{A} 645-4.67 \times \mathrm{A} 663$

Carotenoids $=(1000 \times \mathrm{A} 470-3.27 \times$ chlorophyll a $104 \times$ chlorophyll b) / 229

Carotenoids were expressed in $\mathrm{mg} / 100 \mathrm{~g}$ d.m.

\section{Antioxidant activities}

\section{- ANTIRADICAL ACTIVITY (ABTS)}

The experiments were carried out using an improved ABTS decolorization assay (Re et al., 1999). Free radical scavenging ability was expresses as a Trolox equivalent in $\mathrm{mg}$ per $\mathrm{g}$ of dry mass (d.m.).

\section{- REDUCING POWER (RP)}

Reducing power was determined by the method of Oyaizu (1986). Reducing power was expressed as a Trolox equivalent in mg per $g$ of dry mass (d.m.).

\section{- METAL CHELATING ACTIVITY (CHP)}

Chelating power was determined by the method of Decker and Welch (1990). Chelating power was expressed as an EDTA equivalent (EDTA) in $\mathrm{mg}$ per $\mathrm{g}$ of dry mass (d.m.).

\section{- INHIBITION OF LINOLEIC ACID PEROXIDATION (LPI)}

The inhibition of the hemoglobin-catalyzed peroxidation of linoleic acid was determined according to Groupy et al. (2007). The activity was expressed as a Trolox equivalent (TE) in mg per g of dry mass (d.m.).

\section{Enzymatic activities}

\section{- EXTRACT PREPARATION}

All enzyme extraction procedures were conducted at $4^{\circ} \mathrm{C}$. For phenylalanine ammonia-lyase (PAL) and tyrosine ammonia-lyase (TAL), $200 \mathrm{mg}$ of lyophilized sample were ground with $2 \mathrm{ml}$ extracting buffer $(0.2$ $\mathrm{M}$ boric acid buffer containing, $1 \mathrm{mM}$ EDTA, and 50 $\mathrm{mM} \beta$-mercaptoethanol, $\mathrm{pH} 8.8$ ). The extracts were then homogenized and centrifuged at $12000 \times \mathrm{g}$ at $4^{\circ} \mathrm{C}$ for $30 \mathrm{~min}$, and the supernatant was collected. For polyphenol oxidase (PPO) and guaiacol peroxidase (POD), $200 \mathrm{mg}$ of the lyophilized sample were ground with $4 \mathrm{ml}$ of $100 \mathrm{mM}$ sodium phosphate buffer $(\mathrm{pH}$ 6.4) containing $0.2 \mathrm{~g}$ of polyvinylpyrrolidone. The extracts were then homogenized and centrifuged at 12 $000 \times \mathrm{g}$ at $4^{\circ} \mathrm{C}$ for $30 \mathrm{~min}$, and the supernatants were collected.

\section{- ENZYME ASSAY}

Peroxidase (POD) assay. POD activity was determined using guaiacol as the substrate (Ippolito et al., 2000). The reaction mixture consisted of $0.1 \mathrm{~mL}$ of crude extract and $2 \mathrm{~mL}$ of guaiacol $(8 \mathrm{mM}$, in $100 \mathrm{mM}$ sodium phosphate buffer, $\mathrm{pH}$ 6.4) was incubated for $1 \mathrm{~min}$ at $30^{\circ} \mathrm{C}$. The increase in absorbance at $460 \mathrm{~nm}$ was measured after $1 \mathrm{~mL} \mathrm{H}_{2} \mathrm{O}_{2}(24 \mathrm{mM})$ was added. The activity of POD was expressed as U, where $\mathrm{U}=0.001 \Delta \mathrm{OD} 460 / \mathrm{min}$ under the conditions of the assay. The results were presented as $\mathrm{U}$ per $\mathrm{mg}$ of protein.

Polyphenol oxidase (PPO) assay. For the PPO assay, $100 \mu \mathrm{L}$ of extract were incubated with $2 \mathrm{~mL}$ $0.05 \mathrm{M}$ phosphate buffer $(\mathrm{pH} 7.0)$ and $0.5 \mathrm{~mL} 0.5 \mathrm{M}$ catechol at $24^{\circ} \mathrm{C}$ for $5 \mathrm{~min}$, and absorbance at $398 \mathrm{~nm}$ was measured. The PPO activity was expressed as U, where $\mathrm{U}=0.001 \Delta \mathrm{OD} 398 / \mathrm{min}$ under the conditions of the assay (Galeazzi et al., 1981). The results were presented as $\mathrm{U}$ per $\mathrm{mg}$ of protein.

Tyrosine ammonia-lyase (TAL) assay. For the TAL assay, $100 \mu \mathrm{L}$ of the extract were incubated with $0.9 \mathrm{~mL} 0.02 \mathrm{M} \mathrm{L}$-tyrosine at $30^{\circ} \mathrm{C}$ for $60 \mathrm{~min}$. After incubations, $0.5 \mathrm{~mL} 10 \%$ trichloroacetic acid (TCA) was added to stop the reaction, samples were centrifuged $(15000 \times \mathrm{g}, 10 \mathrm{~min})$ and absorbance at $310 \mathrm{~nm}$ was measured. One unit was defined as the amount of enzyme that produced $1.0 \mu \mathrm{g} p$-coumaric acid per min under the conditions of the assay. The results were presented as U per mg of protein (Assis et al., 2001).

Phenylalanine ammonia-lyase (PAL) assay. For the PAL assay, $300 \mu \mathrm{L}$ of the extract were incubated with $1.2 \mathrm{~mL} 0.02 \mathrm{M} \mathrm{L}$-phenylalanine and $2 \mathrm{~mL}$ of the PAL extracting buffer at $30^{\circ} \mathrm{C}$ for $60 \mathrm{~min}$. After incubations, $0.5 \mathrm{~mL} 10 \%$ TCA was added to stop the reaction, samples were centrifuged $(15000 \times \mathrm{g}, 10 \mathrm{~min})$ and absorbance at $290 \mathrm{~nm}$ was measured. One unit 
Świeca, M. (2016). Elicitation and treatment with precursors of phenolics synthesis improve low-molecular antioxidants and antioxidant capacity of buckwheat sprouts. Acta Sci. Pol. Technol. Aliment., 15(1), 17-28. DOI: 10.17306/J.AFS.2016.1.2

was defined as the amount of enzyme that produced $1.0 \mu \mathrm{g}$ trans-cinnamic acid per min under the conditions of the assay. The results were presented as $\mathrm{U}$ per mg of protein (Assis et al., 2001).

\section{Protein assay}

The proteins content was determined with the Bradford method (Bradford, 1976), using bovine serum albumin as the standard protein.

\section{Statistical analysis}

All experimental results were mean \pm S.D. of three independent experiments $(n=9)$. One-way analysis of variance (ANOVA) and Turkey's post-hoc test were used to compare groups (seeds, as well as control and elicited sprouts) (STATISTICA 6, StatSoft, Inc., Tulsa, USA). Differences were considered significant at $p<0.05$. Data was evaluated using Pearson's correlation coefficients to identify relationships between selected features.

\section{RESULTS}

The main antioxidants present in buckwheat sprouts are phenolics, in particular flavonoids. These compounds are known to be synthesized in the phenylpropanoid pathway and play a pivotal role in the plant's resistance against pathogens, radiation and environmental stresses. In Figure 1, the activities of enzymes involved in phenolic synthesis and metabolism are presented. The activity of peroxidase, an enzyme involved inter alia in lignin synthesis form phenolic constituents, was significantly increased by elicitation in the control sprouts $(\mathrm{C}+\mathrm{E})$, as well as those obtained from seed fed with shikimic acid (Sh and $\mathrm{Sh}+\mathrm{E})$. The
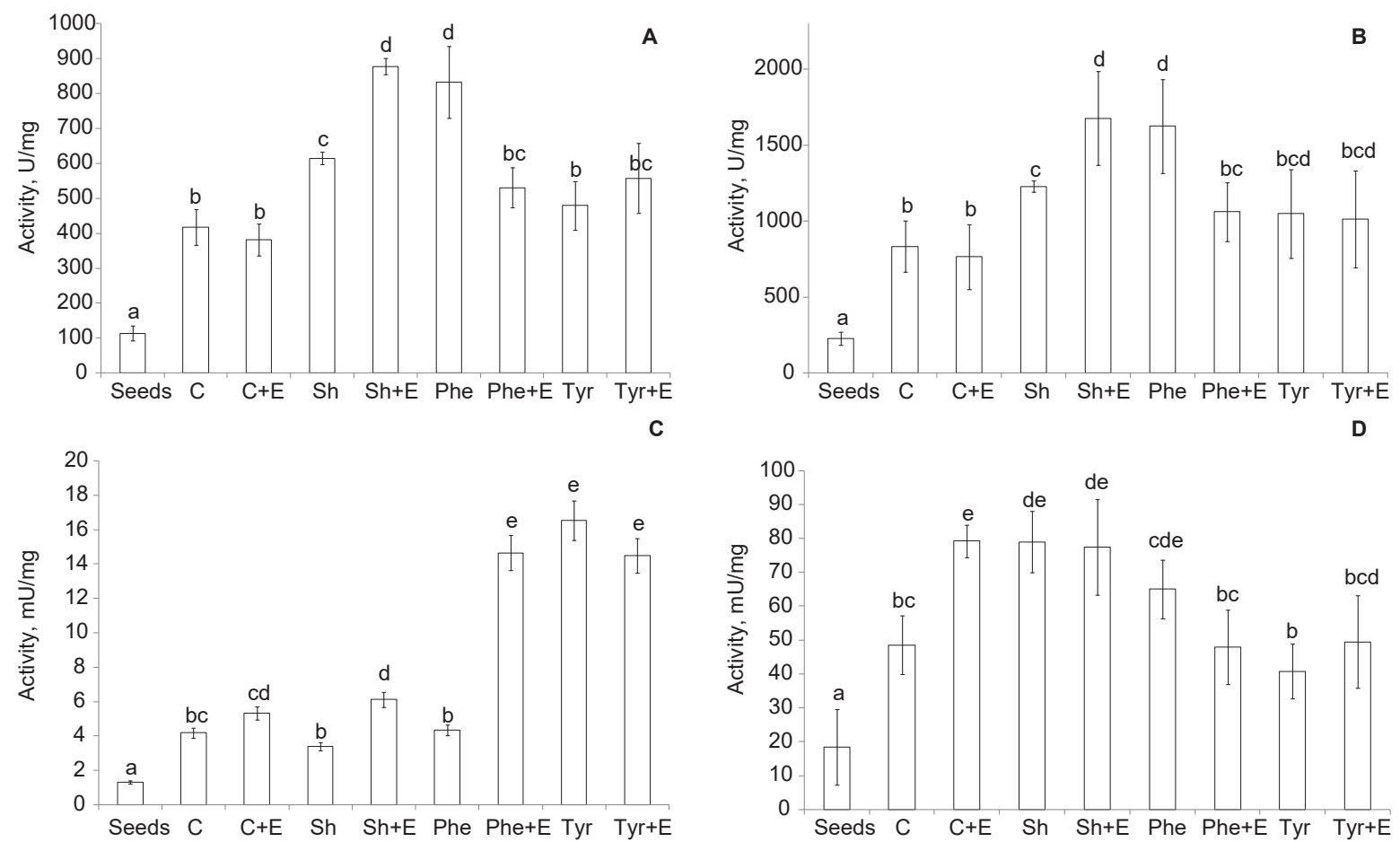

Fig. 1. Influence of elicitation combined with precursor feeding on the activates of enzymes involved in phenolic synthesis and metabolism: A - peroxidase, B - polyphenols oxidase, C - L-tyrosine ammonia-lyase, D - L-phenylalanine ammonia-lyase; $\mathrm{S}$ - seeds, $\mathrm{C}$ - control, $\mathrm{C}+\mathrm{E}$ - elicitation, $\mathrm{Sh}$ - shikimic acid feeding, $\mathrm{Sh}+\mathrm{E}$ - elicitation and shikimic acid feeding, Phe - phenylalanine feeding, Phe $+\mathrm{E}-$ elicitation and phenylalanine feeding, Tyr - tyrosine feeding, Tyr $+\mathrm{E}-$ elicitation and tyrosine feeding. Means in columns followed by different letters are significantly different at $p=0.05$. Each value represents the mean of three independent experiments $( \pm \mathrm{SD})$ 
Świeca, M. (2016). Elicitation and treatment with precursors of phenolics synthesis improve low-molecular antioxidants and antioxidant capacity of buckwheat sprouts. Acta Sci. Pol. Technol. Aliment., 15(1), 17-28. DOI: 10.17306/J.AFS.2016.1.2

activity of polyphenols oxidase was increased in all the sprouts fed with the phenylpropanoids precursors; however, the changes were statistically significant $(p<0.05)$ only in the case of Sh, Sh+E and Phe sprouts - elevations of about $47 \%, 101 \%$ and $95 \%$, respectively (compared to the control). The activities of L-tyrosine ammonia-lyase (TAL) and L-phenylalanine ammonia-lyase (PAL), two enzymes directly involved in phenolic synthesis, were also diversified by the applied modification of sprouting modification. In respect to the control, TAL activity was most effectively induced by seeds soaking with tyrosine - for Tyr and Tyr+E about 4-fold and 3.5-fold, respectively. A significant increase was also determined for elicited sprouts obtained from seeds fed with phenylalanine (Phe+E). The activity of PAL was the highest in the elicited control sprouts $(\mathrm{C}+\mathrm{E})$ and sprouts obtained from seeds fed

Table 1. Phenolic content in buckwheat sprouts - the effect of elicitation and elicitation supported by the phenylpropanoid pathway feeding

\begin{tabular}{lccc}
\hline & $\begin{array}{c}\text { Total phenolics } \\
\mathrm{mg} / \mathrm{g} \mathrm{d} . \mathrm{m} .\end{array}$ & $\begin{array}{c}\text { Condensed } \\
\text { tanins } \\
\mathrm{mg} / \mathrm{g} \mathrm{d} . \mathrm{m} .\end{array}$ & $\begin{array}{c}\text { Total flavonoids } \\
\mathrm{mg} / \mathrm{g} \mathrm{d} . \mathrm{m} .\end{array}$ \\
\hline Seeds & $22.83 \pm 3.07 \mathrm{a}$ & $2.70 \pm 0.05 \mathrm{a}$ & $1.11 \pm 0.36 \mathrm{a}$ \\
$\mathrm{C}$ & $37.68 \pm 1.36 \mathrm{~b}$ & $7.25 \pm 0.33 \mathrm{~b}$ & $5.31 \pm 0.33 \mathrm{~b}$ \\
$\mathrm{C}+\mathrm{E}$ & $37.99 \pm 2.14 \mathrm{bc}$ & $7.25 \pm 0.16 \mathrm{~b}$ & $5.41 \pm 0.14 \mathrm{~b}$ \\
Sh & $41.77 \pm 1.08 \mathrm{bc}$ & $9.47 \pm 0.19 \mathrm{~d}$ & $7.78 \pm 0.43 \mathrm{c}$ \\
Sh+E & $45.56 \pm 1.25 \mathrm{~d}$ & $9.35 \pm 0.49 \mathrm{~cd}$ & $9.06 \pm 0.65 \mathrm{~d}$ \\
Phe & $44.45 \pm 1.71 \mathrm{~cd}$ & $9.12 \pm 0.22 \mathrm{~cd}$ & $5.97 \pm 0.19 \mathrm{~b}$ \\
Phe+E & $39.39 \pm 2.03 \mathrm{bc}$ & $7.59 \pm 0.58 \mathrm{bcd}$ & $5.75 \pm 0.18 \mathrm{~b}$ \\
Tyr & $38.68 \pm 1.29 \mathrm{~b}$ & $7.66 \pm 0.48 \mathrm{bc}$ & $5.30 \pm 0.16 \mathrm{~b}$ \\
Tyr+E & $39.60 \pm 0.59 \mathrm{~b}$ & $8.97 \pm 0.20 \mathrm{c}$ & $5.75 \pm 0.29 \mathrm{~b}$ \\
\hline
\end{tabular}

$\mathrm{S}$ - seeds, C - control, C+E - elicitation, $\mathrm{Sh}-$ shikimic acid feeding, Sh+E - elicitation and shikimic acid feeding, Tyr tyrosine feeding, Tyr $+\mathrm{E}$ - elicitation and tyrosine feeding, Phe - phenylalanine feeding, Phe $+\mathrm{E}-$ elicitation and phenylalanine feeding.

Means in columns followed by different letters are significantly different at $p=0.05$.

Each value represents the mean of three independent experiments $( \pm \mathrm{SD})$. with shikimic acid (Sh and Sh-E), where an increase of about $60 \%$ in respect to control was determined.

Germination significantly $(p<0.05)$ increased the phenolic content - an about 2-fold was observed after 3 days of germination (compared to the seeds). The highest elevation was observed in the sprouts obtained from seeds enriched with shikimic acid (Sh and $\mathrm{Sh}+\mathrm{E}$ ) - total phenolics (by about $10 \%$ and $20 \%$, respectively), condensed tannins (by about $30 \%$ and $28 \%$, respectively), and flavonoids (by about $46 \%$ and $70 \%$, respectively). An increased content of total phenolics and condensed tannins was also determined for sprouts obtained from seeds fed with phenylalanine (Phe) (Table 1). Qualitative-quantitative analysis of main sprout phenolics is presented in Figure 2. Generally, the rutin and chlorogenic acid content were comparable in all the sprouts except for the elicited sprouts obtained from seeds fed with shikimic acid, where an increase was determined. These sprouts were also characterized by significantlly $(p<0.05)$ increased contents of vitexin and isoorientin. Most importantly, feeding with the phenylpropanoid precursor caused a significant $(p<0.05)$, about 2-fold, decrease of orientin content. Except for the Tyr and Tyr-E sprouts, the applied modification of sprouting decreased also the (+)-catechin content (Fig. 2). Analysis of the relationships between main flavonoids content and the activities of enzymes involved in phenolics synthesis, as well as their metabolism showed that both enzymes of the phenylpropanoids pathway (PAL and TAL) take a part in the synthesis of flavonoids (Table 2). Pearson correlation coefficients indicate that peroxidase and polyphenols oxidase (enzymes "consuming" phenolics) influenced negatively only orientin $(\mathrm{R}=-0.64$ and -0.65 , respectively) and $(+)$-catechin $(\mathrm{R}=-0.49$ and -0.49 , respectively) levels.

Though phenolics are the main antioxidants of buckwheat sprouts, the influence of the used treatments on the content of other low-molecular antioxidants, such as ascorbic acid and carotenoids, was also studied (Table 3$)$. Germination significantly $(p<0.05)$ increased the vitamin $\mathrm{C}$ and carotenoids content of sprouts. In the sprouts obtained from seeds fed with the studied precursors of phenolics phenolic the amount of ascorbic acid was significantly higher than that determined for the control sprouts $(\mathrm{C}$ and $\mathrm{C}+\mathrm{E})$. Most importantly, vitamin was generally present in a reduced 
Świeca, M. (2016). Elicitation and treatment with precursors of phenolics synthesis improve low-molecular antioxidants and antioxidant capacity of buckwheat sprouts. Acta Sci. Pol. Technol. Aliment., 15(1), 17-28. DOI: 10.17306/J.AFS.2016.1.2
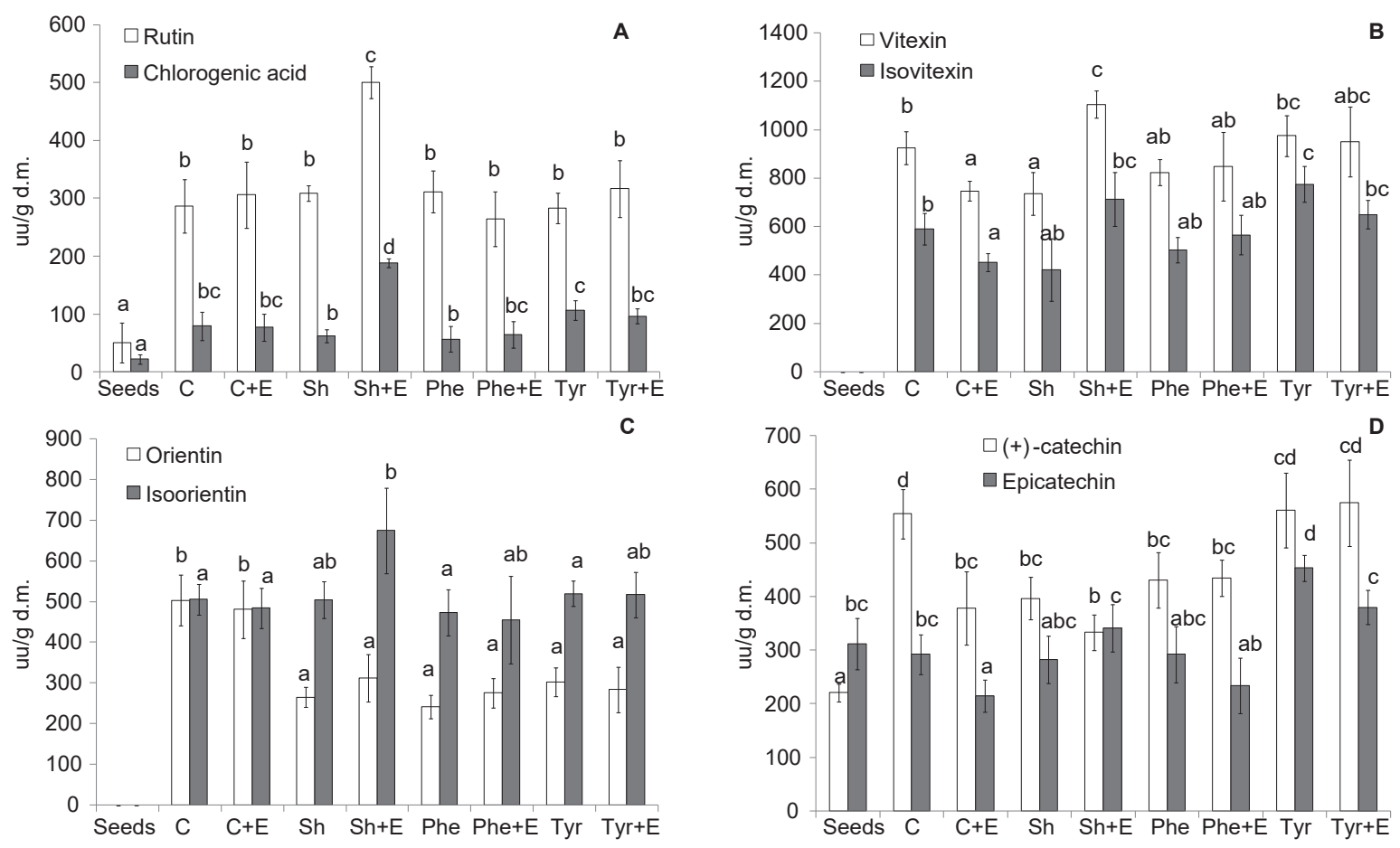

Fig. 2. Influence of elicitation combined with precursor feeding on the content of main phenolics in buckwheat sprouts: A - peroxidase, B - polyphenols oxidase, C - L-tyrosine ammonia-lyase, D - L-phenylalanine ammonialyase; $\mathrm{S}$ - seeds, C - control, C+E - elicitation, $\mathrm{Sh}-$ shikimic acid feeding, $\mathrm{Sh}+\mathrm{E}$ - elicitation and shikimic acid feeding, Phe - phenylalanine feeding, Phe+E - elicitation and phenylalanine feeding, Tyr - tyrosine feeding, Tyr $+\mathrm{E}$ - elicitation and tyrosine feeding. Means in columns followed by different letters are significantly different at $p=$ 0.05 . Each value represents the mean of three independent experiments $( \pm \mathrm{SD})$

Table 2. Relationships between main flavonoids content and the activities of enzymes involved in phenolics synthesis, as well as their metabolism (Pearson correlation coefficients)

\begin{tabular}{lcccc}
\hline & $\begin{array}{c}\text { Pheny- } \\
\text { lalanine } \\
\text { ammonia- } \\
\text { lyase }\end{array}$ & $\begin{array}{c}\text { Tyrosine } \\
\text { ammonia- } \\
\text { lyase }\end{array}$ & $\begin{array}{c}\text { Poly- } \\
\text { phenols } \\
\text { oxidase }\end{array}$ & Peroxidase \\
\hline Isoorientin & 0.33 & -0.13 & 0.52 & 0.54 \\
Orientin & 0.05 & -0.34 & -0.65 & -0.64 \\
Isovitexin & -0.57 & 0.64 & 0.13 & 0.11 \\
Vitexin & -0.31 & 0.34 & 0.34 & 0.36 \\
Rutin & 0.53 & -0.28 & 0.66 & 0.70 \\
(+)-catechin & -0.86 & 0.54 & -0.49 & -0.49 \\
Epicatechin & -0.49 & 0.53 & 0.17 & 0.13 \\
\hline
\end{tabular}

form (dehydroascorbic acid level did not exceed 5\% of total vitamin C). Generally, the used modification of sprouting had only a slight effect on the carotenoids content - the changes did not exceed $10 \%$ (Table 3).

In plant-origin foods, the increase of low-molecular antioxidants usually improves the antioxidant capacity. Antiradical ability and the ability to inhibit lipids peroxidation were most effectively improved in the sprouts obtained from seeds fed with shikimic acid (Sh and $\mathrm{Sh}+\mathrm{E}$ ), where compared to the control sprouts an elevation of about $14 \%$ and $11 \%$ was observed for both variants of sprouting, respectively (Table 4). The highest reducing potential was determined for $\mathrm{Sh}+\mathrm{E}$ and Phe sprouts - an increase by about $8 \%$ and $7 \%$, respectively. The used modification of sprouting, except $\mathrm{C}+\mathrm{E}$, did not affect the chelating power of sprouts. It was observed that the total antioxidant capacity 
Świeca, M. (2016). Elicitation and treatment with precursors of phenolics synthesis improve low-molecular antioxidants and antioxidant capacity of buckwheat sprouts. Acta Sci. Pol. Technol. Aliment., 15(1), 17-28. DOI: 10.17306/J.AFS.2016.1.2

Table 3. Effect of elicitation and elicitation supported by the phenylpropanoid pathway feeding on vitamin $\mathrm{C}$ and carotenoids contents

\begin{tabular}{lcccc}
\hline & $\begin{array}{c}\text { Vitamin C } \\
\mu \mathrm{g} / \mathrm{g} \text { f.m. }\end{array}$ & $\begin{array}{c}\text { Ascorbic acid } \\
\mu \mathrm{g} / \mathrm{g} \text { f.m. }\end{array}$ & $\begin{array}{c}\text { Dehydroascorbic acid } \\
\% \text { of vitamin C }\end{array}$ & $\begin{array}{c}\text { Carotenoids } \\
\mathrm{mg} / 100 \mathrm{~g} \text { d.m. }\end{array}$ \\
\hline Seeds & $2.83 \pm 1.4 \mathrm{a}$ & $1.61 \pm 0.88 \mathrm{a}$ & 43.2 & $2.33 \pm 0.72 \mathrm{a}$ \\
$\mathrm{C}$ & $65.61 \pm 0.63 \mathrm{~b}$ & $63.49 \pm 3.98 \mathrm{~b}$ & 3.23 & $28.51 \pm 3.16 \mathrm{~cd}$ \\
$\mathrm{C}+\mathrm{E}$ & $67.12 \pm 1.50 \mathrm{~b}$ & $61.69 \pm 8.19 \mathrm{~b}$ & 8.10 & $25.97 \pm 1.20 \mathrm{c}$ \\
Sh & $88.81 \pm 11.05 \mathrm{c}$ & $86.15 \pm 13.05 \mathrm{c}$ & 3.00 & $30.63 \pm 1.63 \mathrm{e}$ \\
Sh+E & $81.42 \pm 2.00 \mathrm{c}$ & $79.35 \pm 2.87 \mathrm{c}$ & 2.54 & $27.17 \pm 0.95 \mathrm{~cd}$ \\
Phe & $85.78 \pm 3.56 \mathrm{c}$ & $83.10 \pm 5.96 \mathrm{c}$ & 3.12 & $20.67 \pm 0.98 \mathrm{~b}$ \\
Phe+E & $78.06 \pm 2.48 \mathrm{c}$ & $76.81 \pm 1.66 \mathrm{c}$ & 1.59 & $27.68 \pm 0.99 \mathrm{~d}$ \\
Tyr & $80.95 \pm 0.66 \mathrm{c}$ & $79.96 \pm 1.01 \mathrm{c}$ & 1.23 & $27.50 \pm 1.43 \mathrm{~cd}$ \\
Tyr+E & $80.77 \pm 2.00 \mathrm{c}$ & $76.98 \pm 2.69 \mathrm{c}$ & 4.69 & $26.23 \pm 0.82 \mathrm{c}$ \\
\hline
\end{tabular}

$\mathrm{S}$ - seeds, C - control, C+E - elicitation, Sh - shikimic acid feeding, Sh+E - elicitation and shikimic acid feeding, Tyr - tyrosine feeding, Tyr+E - elicitation and tyrosine feeding, Phe - phenylalanine feeding, Phe $+\mathrm{E}-$ elicitation and phenylalanine feeding.

Means in columns followed by different letters are significantly different at $p=0.05$.

Each value represents the mean of three independent experiments $( \pm \mathrm{SD})$.

Table 4. Effect of elicitation and elicitation supported by the phenylpropanoid pathway feeding on the antioxidant capacity of buckwheat sprouts

\begin{tabular}{lcccc}
\hline & $\begin{array}{c}\text { Antiradical ability } \\
\text { mg TE/g d.m. }\end{array}$ & $\begin{array}{c}\text { Reducing power } \\
\text { mg TE/g d.m. }\end{array}$ & $\begin{array}{c}\text { Inhibition of lipids peroxidation } \\
\text { mg TE/g d.m. }\end{array}$ & $\begin{array}{c}\text { Chelating power } \\
\text { mg EDTA/g d.m. }\end{array}$ \\
\hline Seeds & $4.94 \pm 0.68 \mathrm{a}$ & $12.32 \pm 0.86 \mathrm{a}$ & $8.99 \pm 0.45 \mathrm{~b}$ & $6.24 \pm 0.25 \mathrm{a}$ \\
$\mathrm{C}$ & $12.99 \pm 1.01 \mathrm{~b}$ & $43.74 \pm 3.06 \mathrm{bc}$ & $11.15 \pm 0.28 \mathrm{~d}$ & $8.11 \pm 0.07 \mathrm{c}$ \\
$\mathrm{C}+\mathrm{E}$ & $12.93 \pm 0.68 \mathrm{~b}$ & $43.78 \pm 1.49 \mathrm{~b}$ & $10.04 \pm 0.13 \mathrm{c}$ & $7.75 \pm 0.11 \mathrm{~b}$ \\
Sh & $14.96 \pm 0.54 \mathrm{c}$ & $44.54 \pm 5.79 \mathrm{bc}$ & $12.39 \pm 0.39 \mathrm{e}$ & $8.26 \pm 0.09 \mathrm{c}$ \\
Sh+E & $14.78 \pm 0.47 \mathrm{c}$ & $47.30 \pm 1.80 \mathrm{c}$ & $12.45 \pm 0.43 \mathrm{e}$ & $8.20 \pm 0.05 \mathrm{~cd}$ \\
Phe & $14.64 \pm 0.67 \mathrm{bc}$ & $46.77 \pm 1.93 \mathrm{c}$ & $9.55 \pm 1.14 \mathrm{bcd}$ & $8.16 \pm 0.02 \mathrm{c}$ \\
Phe+E & $13.45 \pm 0.38 \mathrm{~b}$ & $41.46 \pm 3.89 \mathrm{bc}$ & $7.30 \pm 0.10 \mathrm{a}$ & $8.12 \pm 0.11 \mathrm{~cd}$ \\
Tyr & $13.18 \pm 0.34 \mathrm{~b}$ & $41.08 \pm 1.96 \mathrm{~b}$ & $9.79 \pm 1.02 \mathrm{bcd}$ & $8.31 \pm 0.05 \mathrm{~d}$ \\
Tyr+E & $13.44 \pm 0.92 \mathrm{bc}$ & $42.92 \pm 4.77 \mathrm{bc}$ & $12.39 \pm 0.25 \mathrm{e}$ & $8.06 \pm 0.08 \mathrm{c}$ \\
\hline
\end{tabular}

$\mathrm{S}$ - seeds, $\mathrm{C}$ - control, $\mathrm{C}+\mathrm{E}$ - elicitation, $\mathrm{Sh}$ - shikimic acid feeding, $\mathrm{Sh}+\mathrm{E}$ - elicitation and shikimic acid feeding, Tyr - tyrosine feeding, Tyr+E - elicitation and tyrosine feeding, Phe - phenylalanine feeding, Phe $+\mathrm{E}-$ elicitation and phenylalanine feeding. TE - Trolox equivalent, EDTA - ethylenediaminetetraacetic acid.

Means in columns followed by different letters are significantly different at $p=0.05$.

Each value represents the mean of three independent experiments $( \pm \mathrm{SD})$. 
Świeca, M. (2016). Elicitation and treatment with precursors of phenolics synthesis improve low-molecular antioxidants and antioxidant capacity of buckwheat sprouts. Acta Sci. Pol. Technol. Aliment., 15(1), 17-28. DOI: 10.17306/J.AFS.2016.1.2

(according to four complementary methods) of sprouts was most effectively increased by feeding seeds with shikimic acid and further elicitation of sprouts during germination (Table 4).

\section{DISCUSSION}

Modifications of sprouting aimed at overproducing antioxidants usually involve induction of the natural mechanisms of plant resistance (Gawlik-Dziki et al., 2013; Pérez-Balibrea et al., 2011; Świeca et al., 2012; Tsurunaga et al., 2013); however, there are only a few studies concerning the mechanisms of obtaining desirable features. Elicitations usually induce a plant response cascade including inter alia changes in the activities of some enzymes, among which peroxidase, polyphenol oxidase and phenylalanine/tyrosine ammonia lyases should be mentioned. Peroxidase oxidizes phenolics (including flavonoids), whereby ascorbate accepts an electron from phenoxyl or flavonoid radicals. Ascorbate thereby converts to forma monodehydroascorbate radical, which subsequently can become converted to dehydroascorbate. Polyphenol oxidase catalyzes the oxidation of various phenolic substrates, whose polymerization leads to the formation of brown pigments or cell wall structures (Müller et al., 2014). Unfortunately (elicitation by producing oxidative stress) induces the activity of these enzymes, which may negatively influence antioxidant capacity by a reduction of phenolics and ascorbic acid contents (Tomás-Barberán and Espín, 2001; Van Doorn and Ketsa, 2014). Most importantly, in this study the activities of PPO and POD were increased only in the $\mathrm{Sh}, \mathrm{Sh}+\mathrm{E}$ and Phe sprouts, but according to the results (the dehydroascorbic acid level) elicitation did not affect redox status of sprouts.

In response to stress, plants overproduce inter alia phenolic compounds acting as antioxidants, signal compounds and/or substrates for physical barriers synthesis. Phenolics are mainly produced in the phenylpropanoid pathway, thus the induction of this metabolic pathway with elicitors seems to be an effective and simple tool for improving their level. So far, polyphenol synthesis was effectively increased by elicitation in both cell cultures (Matkowski, 2008; Zhao et al., 2014), as well as in low-processed food (Baenas et al., 2014). The effect of UV radiation (wavelengths $260-320 \mathrm{~nm}, 280-320 \mathrm{~nm}$, and 300-320 nm) on the production of flavonoid compounds in buckwheat sprouts was studied by Tsurunaga et al. (2013). The results obtained in the cited studies show that UV-B $(>300 \mathrm{~nm})$ irradiation is effective in the production of buckwheat sprouts with increased anthocyanins, rutin and DPPH radical scavenging activity. Contrary to this study, the increase in the ability to quench free radicals was significant (by about $35 \%$ ). It may be explained by the fact that metabolism of 7-dayold buckwheat seedlings is strictly directed on flavonoid production (the effects of elicitation are clearly visible). The amount of phenolic compounds and carotenoids in the buckwheat sprouts was also improved by treatment with various concentrations of $\mathrm{NaCl}(10,50,100$, and $200 \mathrm{mM}$ ) (Lim et al., 2012). In case of 3-day-old sprouts the most effective was treatment with $100 \mathrm{mM}$ $\mathrm{NaCl}$ (which effected an almost $100 \%$ increase). The effects of elicitation with methyl jasmonate (MeJA) on phytochemical production in buckwheat sprouts cultivated under dark conditions $(0,1,3,5$, and $7 \mathrm{~d})$ were also studied (Kim et al., 2011). Similarly to this study, the cited investigators found chlorogenic acid, catechin, isoorientin, orientin, rutin, vitexin and quercitrin as the main phenolics of sprouts; however, an increase of total phenolic content in elicited sprouts was higher. The pattern of antioxidant activity reflected the changes in total phenolic content - after 3 days of sprouting differences could be observed between the antioxidant activities of the control and treated sprouts (Kim et al., 2011). These observations fully confirm the results obtained in this study. The accumulation of phenolic compounds resulted from the stimulation of the phenylpropanoid pathway (activity of PAL and TAL; Table 2, Fig. 1). An increase of enzymes involved in phenolic synthesis was also observed in sweet basil after treatment with methyl jasmonate, spermine and epibrassinolide, and in radish sprout after spraying with exogenous methyl jasmonate (Kim et al., 2006). Most importantly, in buckwheat sprouts total phenolic content is strongly, positively correlated with PAL activity (Ren and Sun, 2014). A significant increase of PAL but also TAL activity was also observed in this study after elicitation with Salix bark infusion; however, the effect was strongly dependent on precursor feeding, which may indicate that under stress conditions phenolic synthesis is mainly limited by the availability of their precursor. This hypothesis seems to be confirmed by other studies, e.g., improved 
Świeca, M. (2016). Elicitation and treatment with precursors of phenolics synthesis improve low-molecular antioxidants and antioxidant capacity of buckwheat sprouts. Acta Sci. Pol. Technol. Aliment., 15(1), 17-28. DOI: 10.17306/J.AFS.2016.1.2

accumulation of phenylethanoid glycosides in suspension culture of Cistanche salsa (Liu et al., 2007), naringenin and phenylalanine feeding in anthocyanins synthesis in Rudbeckia (Luczkiewicz and Cisowski, 2001) or an effect of growth regulators and phenylalanine on phenolic compounds in sweet basil (Koca and Karaman, 2015). In the study of Świeca et al. (2014c), supplementation of seeds with shikimic acid, phenylalanine and tyrosine (combined with UV-B treatment) for improving the phenolic content and antioxidant activity of lentil sprouts was successfully applied. This strategy has also been employed for broccoli sprouts; however, feeding with methionine and tryptophan (precursors of aliphatic and indolic glucosinolates) did not result in any significant elevation of the glucosinolates content (Pérez-Balibrea et al., 2011).

\section{CONCLUSION}

In this study buckwheat sprouts were used as a biotechnological module. Elicitation with infusion of willow bark supported by feeding with the phenylpropanoid pathway precursors is a metabolic engineering tool aimed to improve the functional quality of the sprouts - namely, an overproduction of low-molecular antioxidants. Metabolomic and biochemical analysis provides information concerning the mechanisms of desirable features gaining. Without any undesirable change in the metabolism of sprouts (redox potential, activities of polyphenol oxidase and peroxidase), the applied treatments significantly increased the lowmolecular weight antioxidants content and affected the antioxidant capacity of the sprouts. This study revealed that the accumulation of these compounds was caused by the stimulation of two main enzymes of the phenylpropanoid pathway (tyrosine ammonia-lyase and phenylalanine ammonia-lyase). Consequently, the obtained results could be used to better understand the effects of elicitation and precursor feeding on the production of pro-health phytochemicals in buckwheat sprout, as well as to define how this technology improves their functional quality.

\section{REFERENCES}

Assis, J. S., Maldonado, R., Munoz, T., Escribano, M. I., Merodio, C. (2001). Effect of high carbon dioxide concentration on PAL activity and phenolic contents in ripening Cherimoya fruit. Postharvest. Biol. Technol., 23, $33-39$.

Baenas, N., García-Viguera, C., Moreno, D. A. (2014). Elicitation, a tool for enriching the bioactive composition of foods. Molecules, 19(9), 13541-13563.

Bradford, M. M. (1976). A rapid and sensitive method for the quantitation of microgram quanti-ties of protein utilizing the principle of protein - dye binding. Anal. Biochem., 7(72), 248-254.

Campos, F. M., Ribeiro, S. M. R., Della Lucia, C. M., Pinheiro-Sant'Ana, H. M., Stringheta, P. C. (2009). Optimization of methodology to analyze ascorbic and dehydroascorbic acid in vegetables. Química Nova, 32(1), 87-91.

Carocho, M., Ferreira, I. C. F. R. (2013). A review on antioxidants, prooxidants and related controversy. Natural and synthetic compounds, screening and analysis methodologies and future perspectives. Food Chem. Toxicol., 51(1), 15-25.

Decker, E. A., Welch, B. (1990). Role of ferritin as a lipid oxidation catalyst in muscle food. J. Agric. Food Chem., 38(3), 674-677.

Durak, A., Gawlik-Dziki, U. (2014). The study of interactions between active compounds of coffee and willow (Salix sp.) bark water extract. BioMed Res. Int., Article ID 386953, http://dx.doi.org/10.1155/2014/386953

Fang, Y.-Z., Yang, S., Wu, G. (2002). Free radicals, antioxidants, and nutrition. Nutrition, 18(10), 872-879.

Galeazzi, M. A. M., Sgarbieri, N., Costantinides, S. M. (1981). Isolation, purification and physiochemical characterization of polyphenol oxidase from dwarf variety of banana (Musa Cavendishii). J. Food Sci., 46, 150-155.

Gallie, D. R. (2013). Increasing vitamin C content in plant foods to improve their nutritional value-successes and challenges. Nutrients, 5(9), 3424-3446.

Gawlik-Dziki, U., Jezyna, M., Świeca, M., Dziki, D., Baraniak, B., Czyz, J. (2012). Effect of bioaccessibility of phenolic compounds on in vitro anticancer activity of broccoli sprouts. Food Res. Inter., 49(1), 469-476.

Gawlik-Dziki, U., Świeca, M., Dziki, D., Sugier, D. (2013). Improvement of nutraceutical value of broccoli sprouts by natural elicitors. Acta Sci. Pol. Hortorum, 12(1), 129-140.

Groupy, P., Vulcain, E., Caris-Veyrat, C., Dangles, O. (2007). Dietary antioxidants as inhibitors of the hemeinduced peroxidation of linoleic acid. Mechanism of action and synergism. Free Rad. Biol. Med., 43, 933-943.

Ippolito, A., Elghaouth, A., Wilson C. L., Wisniewski, M. (2000). Control of postharvest decay of apple fruit by 
Świeca, M. (2016). Elicitation and treatment with precursors of phenolics synthesis improve low-molecular antioxidants and antioxidant capacity of buckwheat sprouts. Acta Sci. Pol. Technol. Aliment., 15(1), 17-28. DOI: 10.17306/J.AFS.2016.1.2

Aureobasidium pullulans and induction of defense responses. Postharvest Biol. Technol., 19, 265-272.

Khattak, A. B., Zeb, A., Bibi, N., Khalil, S. A., Khattak, M. S. (2007). Influence of germination techniques on phytic acid and polyphenols content of chickpea (Cicer arietinum L.) sprouts. Food Chem., 104(3), 1074-1079.

Kim, H., Chen, F., Wang, X., Choi, J. (2006). Effect of methyl jasmonate on phenolics, isothiocyanate, and metabolic enzymes in radish sprout (Raphanus sativus L.). J. Agric. Food Chem., 54(19), 7263-7269.

Kim, H. J., Park, K. J., Lim, J. H. (2011). Metabolomic analysis of phenolic compounds in buckwheat (Fagopyrum esculentum M.) sprouts treated with methyl jasmonate. J. Agric. Food Chem., 59, 5707-5713.

Koca, N., Karaman, Ş. (2015). The effects of plant growth regulators and L-phenylalanine on phenolic compounds of sweet basil. Food Chem., 166, 515-521.

Lamaison, J. L. C., Carnet, A. (1990). Teneurs en principaux flavonoids des fleurs de Crataegeus monogyna Jacq et de Crataegeus laevigata (Poiret D. C) en fonction de la vegetation. Pharm Acta Helv., 65, 315-320.

Lim, J., Park, K., Kim, B., Jeong, J., Kim, H. (2012). Effect of salinity stress on phenolic compounds and carotenoids in buckwheat (Fagopyrum esculentum M.) sprout. Food Chem., 135(3), 1065-1070.

Lin, K.-H., Huang, M.-Y., Huang, W.-D., Hsu, W.-D., Yang, Z.-W., Yang, C.-M. (2013). The effects of red, blue, and white light-emitting diodes on the growth, development, and edible quality of hydroponically grown lettuce ( $\mathrm{Lac}$ tuca sativa L. var. capitata). Sci. Hort., 150, 86-91.

Liu, J., Guo, Z., Zeng, Z. (2007a). Improved accumulation of phenylethanoid glycosides by precursor feeding to suspension culture of Cistanche salsa. Biochem. Eng. J., 33(1), 88-93.

Liu, R., Hu, Y., Li, J., Lin, Z. (2007b). Production of soybean isoflavone genistein in non-legume plants via genetically modified secondary metabolism pathway. Metabol. Eng., 9(1), 1-7.

Luczkiewcz, M., Cisowski, W. (2001). Optimisation of the second phase of a two phase growth system for anthocyanin accumulation in callus cultures of Rudbeckia hirta. Plant Cell Tiss. Org., 65(1), 57-68.

Matkowski, A. (2008). Plant in vitro culture for the production of antioxidants - A review. Biotechnol. Adv., 26(6), $548-560$

Müller, A., Noack, L., Greiner, R., Stahl, M. R., Posten C. (2014). Effect of UV-C and UV-B treatment on polyphenol oxidase activity and shelf life of apple and grape juices. Innov. Food Sci. Emerg., 26, 498-504.
Oyaizu, M. (1986). Studies on products of browning reaction - Antioxidative activities of products of browning reaction prepared from glucosamine. Jpn. J. Nutr., 44, 307-315.

Pérez-Balibrea, S., Moreno, D. A., García-Viguera, C. (2011). Improving the phytochemical composition of broccoli sprouts by elicitation. Food Chem., 129(1), 35-44.

Re, R., Pellegrini, N., Proteggente, A., Pannala, A., Yang, M., Rice-Evans, C. (1999). Antioxidant activity applying an improved ABTS radical cation decolorization assay. Free Rad. Biol. Med., 26(9-10), 1231-1237.

Ren, S., Sun, J. (2014). Changes in phenolic content, phenylalanine ammonia-lyase (PAL) activity, and antioxidant capacity of two buckwheat sprouts in relation to germination. J. Funct. Foods, 7(1), 298-304.

Shetty, K., Mccue, P. (2003). Phenolic antioxidant biosynthesis in plants for functional food application, integration of systems biology and biotechnological approaches. Food Biotechnol., 17, 67-97.

Singleton, V. L., Orthofer, R., Lamuela-Raventos, R. M. (1974). Analysis of total phenols and other oxidation substrates and antioxidants by means of Folin-Ciocalteu reagent. Methods Enzymol., 299, 152-178.

Sun, B., Ricardo-Da-Silva, J. M., Spranger, I. (1998). Critical factors of vanillin assay for catechins and proanthocyanidins. J. Agric. Food Chem., 46(10), 4267-4274.

Świeca, M., Gawlik-Dziki, U., Kowalczyk, D., Złotek, U. (2012). Impact of germination time and type of illumination on the antioxidant compounds and antioxidant capacity of Lens culinaris sprouts. Sci. Horti., 140, 87-95.

Świeca, M., Baraniak, B. (2014a). Influence of elicitation with $\mathrm{H}_{2} \mathrm{O}_{2}$ on phenolics content, antioxidant potential and nutritional quality of Lens culinaris sprouts. J. Sci. Food Agric., 94(3), 489-496.

Świeca, M., Baraniak, B. (2014b). Nutritional and antioxidant potential of lentil sprouts affected by elicitation with temperature stress. J. Agric. Food Chem., 62(14), 3306-3313.

Świeca, M., Sęczyk, Ł., Gawlik-Dziki, U. (2014c). Elicitation and precursor feeding as tools for the improvement of the phenolic content and antioxidant activity of lentil sprouts. Food Chem., 161, 288-295.

Świeca, M. (2015). Elicitation with abiotic stresses improves pro-health constituents, antioxidant potential and nutritional quality of lentil sprouts. Saudi J. Biol. Sci., 22(4), 409-416.

Świeca, M., Dziki, D. (2015). Improvement in sprouted wheat flour functionality: effect of time, temperature and elicitation. Inter. J. Food Sci. Technol. DOI: 10.1111/ ijfs. 12881 
Świeca, M. (2016). Elicitation and treatment with precursors of phenolics synthesis improve low-molecular antioxidants and antioxidant capacity of buckwheat sprouts. Acta Sci. Pol. Technol. Aliment., 15(1), 17-28. DOI: 10.17306/J.AFS.2016.1.2

Tomás-Barberán, F. A., Espín, J. C. (2001). Phenolic compounds and related enzymes as determinants of quality in fruits and vegetables. J. Sci. Food Agric., 81(9), 853-876.

Tsurunaga, Y., Takahashi, T., Katsube, T., Kudo, A., Kuramitsu, O., Ishiwata, M., Matsumoto, S. (2013). Effects of UV-B irradiation on the levels of anthocyanin, rutin and radical scavenging activity of buckwheat sprouts. Food Chem., 141(1), 552-556.
Van Doorn, W. G., Ketsa, S. (2014). Cross reactivity between ascorbate peroxidase and phenol (guaiacol) peroxidase. Postharvest Biol. Technol., 95, 64-69.

Yuan, S., Lin, H. H. (2008). Role of salicylic acid in plant abiotic stress. Z. Naturforsch. C, 63(5-6), 313-320.

Zhao, J., Xiang, D., Peng, L., Zou, L., Wang, Y., Zhao, G. (2014). Enhancement of rutin production in Fagopyrum tataricum hairy root cultures with its endophytic fungal elicitors. Prep. Biochem. Biotechnol., 44(8), 782-794. 